TELAGA BAHASA

Volume 5

No. 2 Desember 2017

Halaman 335-352

\title{
POLA PEMILIHAN BAHASA BERDASARKAN \\ PERISTIWA BAHASA DAN KATEGORI UMUR: \\ KASUS PEMILIHAN BAHASA ETNIK BUGIS PERANTAU \\ DALAM RANAH KELUARGA DI KABUPATEN DONGGALA
}

(The Pattern of Language Selection Based on Language Event and Age Category:

The Case on Language Selection of Buginese in Family Domain in Donggala Regency)

\section{Tamrin}

Balai Bahasa Provinsi Sulawesi Tengah

Jalan Untad I, Bumi Roviga, Tondo, Palu 94118

Email: thamrin21@ymail.com

\begin{abstract}
Abstrak
Interaksi sosial dalam masyarakat multibahasa dan tersedianya beberapa bahasa atau ragam bahasa, menuntut tiap-tiap penutur untuk mampu memilih secara tepat bahasa atau ragam bahasa yang sesuai dengan situasi komunikasi. Dengan mengangkat kasus pola pemilihan bahasa berdasarkan peristiwa bahasa dan kategori umur dalam kasus pemilihan bahasa etnik Bugis perantau di Kabupaten Donggala, penelitian ini bertujuan (1) mendeskripsikan pola pemilihan bahasa etnik Bugis dalam ranah keluarga berdasarkan peristiwa bahasa kategori umur di Kabupaten Donggala (2) menganalisis faktor-faktor yang mendasari pemilihan bahasa etnik Bugis dalam ranah keluarga berdasarkan peristiwa bahasa kategori umur di Kabupaten Donggala. Metode yang digunakan adalah pendekatan sosiolinguistik dengan teknik kuesioner, wawancara, pengamatan, dan perekaman, kemudian dianalisis berdasarkan presentase pola pemilihan bahasa etnik Bugis dalam ranah keluarga. Hasil analisis menunjukkan bahwa etnik Bugis di Kabupaten Donggala masih dominan memilih bahasa Bugis sebagai alat komunikasi dalam ranah keluarga berdasarkan peristiwa bahasa dan kategori umur. Umur 28-49 dan umur 50 tahun ke atas masih kuat mempertahankan dan memilih menggunakan bahasa Bugis dalam ranah keluarga, sementara umur $11-15$ tahun dan 16-27 tahun pemilihan $\mathrm{BB}$ dalam peristiwa bahasa sudah mulai menurun.
\end{abstract}

Kata kunci: pemilihan bahasa, ranah keluarga, peristiwa bahasa, bahasa Bugis, faktor umur 


\begin{abstract}
The social interaction in multilingual societies and the availability of multiple languages requires each speaker to have the ability to precisely choose the language or variety of languages which appropriate to the communication situation. By raising the case of language selection patterns based on language events and age categories in the language selection of Bugis ethnic in Donggala Regency, this study aimed to (1) describe the pattern of language selection in family domain of Bugis ethnic based on the language event and age category, and (2) analyse the factors underlying the selection of languages based on the language event and age category. The method used is a sociolinguistic approach with questionnaires, interviews, observations, and recording techniques, then the data had been analyzed based on the percentage pattern of the language selection. The result indicated that Bugisnese ethnic in Donggala Regency still chooses Bugisnese language as their communication tool $n$ based on the event of language and age category. The Age of 28-49 and 50 years and above strongly maintain and choose to use Bugisnese language, while among the 11-15 years old and above the use of Bugis language are beginning to decline.
\end{abstract}

Keyword: language selection, family domain, language event, Bugis language, age category.

\section{PENDAHULUAN}

Kesantunan dalam berbahasa seseorang tercermin dalam etika dan tatacara berkomunikasi. Salah satu etika berkomunikasi adalah menghormati dan menyesuaikan norma-norma budaya dalam masyarakat. Jika hal tersebut dilanggar, seseorang dianggap tidak beretika, tidak beradat, dan tak berbudaya. Pandangan ini memberikan penjelasan bahwa tata cara berkomunikasi dititikberatkan dalam budaya dan kebiasaan masyarakat sehingga dapat mencerminkan keperibadian seseorang.

Kesantunan dalam berbahasa seseorang tidak terlepas dari pola pemilihan bahasanya. Pemilihan bahasa merupakan masalah yang kompleks. Setiap anggota masyarakat harus memilih bahasa atau ragam bahasa dalam berinteraksi. Pemilihan bahasa atau ragam bahasa itu tidak bersifat acak, melainkan harus mempertimbangkan berbagai faktor, seperti siapa yang berbicara, kepada siapa, tentang topik apa, di mana peristiwa tutur itu berlangsung. Seorang penutur harus berhati-hati dalam melakukan strategi pemilihan bahasa pada suatu peristiwa tutur. Sekurang-kurangnya harus memperhatikan dua hal, yaitu status sosial dan keakraban mitra tutur, sebab ketidaktepatan pilihan bahasa penutur terhadap lawan tutur sering menimbulkan 
ketidaknyamanan dalam komunikasi atau komunikasi menjadi tidak lancar. Misalnya, lawan tutur yang merasa lebih tinggi tingkat sosialnya daripada penutur akan merasa tersinggung atau merasa kurang dihormati apabila si penutur menggunakan ragam yang terlalu rendah. Pada peristiwa seperti ini mungkin berakibat lawan tutur tidak menanggapi dan menganggapnya sebagai orang yang sombong dan tidak tahu diri.

Sejalan dengan itu, Fasold (1984: 180), mengatakan bahwa pemilihan bahasa yaitu memilih "sebuah bahasa secara keseluruhan" (whole language) dalam suatu komunikasi. Seseorang yang menguasai dua bahasa atau lebih harus memilih bahasa mana yang akan ia gunakan. Misalnya, seseorang yang mengusai bahasa Bugis, selanjutnya disingkat (BB) dan bahasa Indonesia, selanjutnya disingkat (BI) harus memilih salah satu di antara kedua bahasa itu ketika berbicara kepada orang lain dalam peristiwa komunikasi. Dalam hal memilih bahasa terdapat tiga jenis pilihan, pertama dengan memilih satu variasi dari bahasa yang sama (intra-language-variation), apabila seorang penutur BB berbicara kepada kepala desa dengan menggunakan $\mathrm{BB}$, ia telah melakukan pilihan bahasa yang pertama. Kedua, dengan alih kode (code-swicthing), artinya menggunakan satu bahasa pada satu keperluan dan menggunakan bahasa yang lain pada keperluan lain. Ketiga, dengan melakukan campur kode (code-mixing), artinya menggunakan satu bahasa tertentu dengan dicampuri serpihan-serpihan dari bahasa lain.

Berdasarkan hal tersebut, penulis mengkaji salah satu faktor yang berpengaruh dalam pemilihan bahasa etnik Bugis di Kabupaten Donggala khususnya di Kecamatan Sojol Utara yaitu faktor peristiwa bahasa berdasarkan kategori umur.

Etnik Bugis di Kabupaten Donggala merupakan etnik pendatang (perantau) dari Sulawesi Selatan yang membawa bahasa dan budayanya sebagai alat berinteraksi antaretnik dan tetap mempertahankan budayanya untuk bersosialisasi dengan etnik setempat. Kabupaten Donggala khususnya Kecamatan Sojol Utara merupakan daerah tingkat dua di Sulawesi Tengah yang mayoritas penduduknya beretnik Dampal. Selain etnik Dampal, juga terdapat etnik Bugis, Kaili, Mandar, Jawa, dan Gorontalo.

Pemilihan bahasa dalam interaksi sosial masyarakat dwibahasa/multibahasa disebabkan oleh berbagai faktor sosial dan budaya. Evin-Tripp mengidentifikaskan empat faktor utama sebagai penanda pemilihan bahasa penutur dalam interkasi sosial, salah satunya adalah partisipan dalam interkasi. Faktor tersebut mencakup beberapa hal, salah satunya adalah 
pemilihan bahasa berdasarkan peristiwa bahasa dan kategori umur. Peristiwa bahasa adalah sebuah aktivitas berlangsungnya interaksi linguistik dalam satu bentuk ujaran atau lebih yang melibatkan dua pihak, yaitu penutur dan lawan tutur, dengan satu pokok tuturan, dalam waktu, tempat, dan situasi tertentu (Chaer, 2010: 47). Dengan kata lain, tidak dapat dikatakan bahwa dalam setiap proses komunikasi pasti terjadi juga peristiwa tutur atau peristiwa bahasa. Interaksi yang berlangsung antara seorang pedagang pasar dan pembeli pada waktu tertentu dengan menggunakan bahasa sebagai alat komunikasinya adalah sebuah peristiwa tutur. Hal yang sama juga terjadi dan kita dapati dalam acara diskusi, di ruang kuliah, rapat dinas di kantor, sidang di pengadilan, dan sebagainya.

Apabila pola pemilihan bahasa dikaitkan dengan peristiwa bahasa dan umur, berbagai penelitian menunjukkan bahwa umur (sebagaimana halnya gender, kelas sosial, dan asal-usul etnik) merupakan faktor penentu posisi seseorang dalam masyarakat, yang menjadi faktor penting penyebab keanekaragaman berbahasa (Singh and Peccei, 2004: 114). Setiap tingkatan umur biasanya menggunakan tuturan yang khas. Tuturan anak-anak biasanya berbeda dengan tuturan remaja, orang dewasa, maupun orang tua. Usia adalah salah satu faktor penentu utama keanekaragaman bahasa.

Penelitian tentang hubungan antara usia dan bahasa, khususnya yang terkait dengan keanekaragaman berbahasa, banyak yang diarahkan untuk melihat fenomena perilaku berbahasa seseorang seiring dengan berubahnya usia sosial, bukan usia biologis seseorang. Dengan kata lain, kajian perilaku berbahasa seseorang berkaitan lebih erat dengan usia sosialnya yang dipengaruhi oleh usia biologisnya. Sejumlah penelitian tentang hubungan antara perilaku berbahasa seseorang dengan perubahan usia sosialnya mengungkapkan bahwa semakin tua seseorang maka dia akan semakin konservatif (Aziz, 2003: 241). Hal ini terlihat dari semakin tingginya kepedulian seseorang terhadap penggunaan ragam standar dan kosa kata formal seiring dengan bertambahnya usia, sebagai akibat dari tekanan atau tuntutan yang diperoleh di tempat kerja. Akan tetapi ketika memasuki usia pensiun, perilaku berbahasa kembali ke ragam santai sehubungan dengan menurunnya hasrat untuk bersaing dalam memperoleh kekuasaan (Labov, dalam Aziz, 2003: 241). Sedangkan kelompok usia remaja cenderung berada pada posisi selalu ingin memberontak terhadap aturan-aturan kebahasaan yang dianjurkan atau digunakan orang tua. 
Ada tiga masalah penelitian yang ingin dijawab dalam penelitian ini (1) bagaimanakah pola pemilihan bahasa etnik Bugis dalam ranah keluarga berdasarkan peristiwa bahasa dan kategori umur di Kabupaten Donggala? (2) faktor-faktor apakah yang mendasari pemilihan bahasa etnik Bugis dalam ranah keluarga berdasarkan peristiwa bahasa kategori umur di Kabupaten Donggala? Tujuan penelitian ini adalah (1) mendeskripsikan pola pemilihan bahasa etnik bugis dalam ranah keluarga berdasarkan peristiwa bahasa kategori umur di Kabupaten Donggala (2) menganalisis faktor-faktor yang mendasari pemilihan bahasa etnik Bugis dalam ranah keluarga berdasarkan peristiwa bahasa kategori umur di Kabupaten Donggala.

Secara teoretis, penelitian ini diharapkan bermanfaat sebagai sumbangan bagi pengembangan khazanah keilmuan dalam kajian sosiolinguistik, khususnya dalam bidang pemilihan bahasa, ragam bahasa, dialek, dan variasi bahasa. Secara praktis, penelitian ini diharapkan sebagai usaha peningkatan saling pengertian antarmasyarakat pemakai bahasa yang bersangkutan dan usaha kesalahpahaman sebagai akibat penggunaan lebih dari satu bahasa. Selanjutnya, hasil penelitian ini bermanfaat dalam proses penentuan objek yang sama atau berbeda dari penelitian ini sehingga diperoleh informasi yang lebih komprehensif tentang pola-pola komunikasi dan pemilihan bahasa pada masyarakat multibahasa.

\section{TEORI}

Pada dasarnya, bahasa merupakan bagian yang tidak terpisahkan dari suatu sistem sosial. Dalam setiap komunikasi manusia saling menyampaikan informasi yang dapat berupa pikiran, gagasan, maksud, perasaan, maupun emosi secara langsung. Para sosiolinguis mempertanyakan keberadaan variasi bahasa dari berbagai tataran yang bukan merupakan sekadar performansi sebagai akibat kondisi-kondisi gramatikal yang tidak relevan, tetapi adanya benar-benar diakibatkan oleh bermacammacam faktor ekstralingual sebagai pencerminan dari sebuah masyarakat bahasa yang selalu bersifat heterogen (Wijana, 2012: 12-13).

Seseorang tidak lagi dipandang sebagai individu yang terpisah dari yang lain di dalam masyarakat. Ia merupakan anggota dari kelompok sosialnya. Oleh karena itu, bahasa dan pemakaian bahasanya tidak diamati secara individual, tetapi selalu dihubungkan dengan kegiatannya di dalam masyarakat. Dengan kata lain, bahasa tidak saja dipandang sebagai gejala individual tetapi juga sebagai gejala sosial. Sebagai 
gejala sosial, bahasa dan pemakaian bahasa tidak hanya ditentukan oleh faktor linguistik tetapi juga oleh faktor non-linguistik, antara lain adalah faktor sosial. Faktor-faktor sosial yang mempengaruhi pemakaian bahasa misalnya status sosial, tingkat pendidikan, umur, tingkat ekonomi, jenis kelamin dan sebagainya. Di samping itu pemakaian bahasa juga dipengaruhi oleh faktor-faktor situasional. Menurut Fishman pemilihan penggunaan bahasa oleh penutur dalam sebuah peristiwa bahasa tidak terjadi secara acak, melainkan harus mempertimbangkan beberapa faktor yaitu siapa yang berbicara, siapa lawan bicaranya, topik apa yang dibicarakan, dan di mana peristiwa tutur itu terjadi (Wijana, 2012: 7).

Di dalam setiap peristiwa interaksi verbal atau proses komunikasi, selalu terdapat beberapa komponen yang mengambil peranan dan terlibat dalam peristiwa tersebut. Bell (1976: 75) menyatakan secara tradisional terdapat tiga komponen yang telah lama diakui sebagai komponen utama dari sebuah peristiwa atau situasi komunikasi yaitu: penutur (speaker), lawan tutur (hearer), dan topik pembicaraan. Dengan kata lain dalam setiap proses komunikasi yang terjadi antara penutur dan lawan tutur terjadi juga apa yang disebut peristiwa tutur atau peristiwa bahasa (speech event).
Terkait dengan pola pemilihan bahasa berdasarkan peristiwa bahasa dan kategori umur pada masyarakat multibahasa, dikemukakan pendekatan kajian pemilihan bahasa. Fasold (1984: 183) mengemukakan bahwa dalam pemilihan bahasa ada tiga pendekatan yang dapat dilakukan, yaitu pendekatan sosiologi, psikologi sosial, dan antropologi. Penulis dalam penelitian ini menggunakan pendekatan sosiologi, karena kajian ini berkaitan dengan analisis ranah. Pendekatan ini pertama kali dikemukakan oleh Fishman (1970). Menurut pola ini, ranah merupakan konstalasi faktor lokasi, topik, dan partisipan. Ditambahkannya (dalam Amir, 2010: 35) bahwa ranah adalah konsep teoritis yang menandai satu situasi interaksi yang didasarkan pada suatu pengalaman yang sama.

Sehubungan dengan uraian tersebut, teori yang digunakan dalam penelitian ini adalah teori pemilihan bahasa yang diadopsi dari teori Fishman yang mengemukakan bahwa dalam penggunaan bahasa ada konteks-konteks sosial yang melembaga (institusional context) yang disebut ranah. Ranah tersebut menurut Fishman (1972b:118), yaitu ranah keluarga, ranah ketetanggaan, ranah kerja, ranah agama, dan ranah pemerintahan. Namun, dalam penelitian ini difokuskan pada penggunaan bahasa dalam ranah keluarga berdasarkan 
peristiwa bahasa dan kategori umur. Kategori umur yang digunakan dalam tulisan ini ada empat kelompok, yaitu umur $11-15$ tahun, umur 16-27 tahun, umur 28-49 tahun, dan umur 50 tahun ke atas. Selanjutnya, hubungan peran yang digunakan komunikasi antara anggota keluarga, yaitu kakek/nenek, ayah/ibu, kakak/adik, putra/putri dan suami/istri dalam berbagai topik pembicaraan. Untuk melengkapi kajian tersebut, digunakan pula teori Platt, (1977) yang berpendapat bahwa dimensi identitas sosial merupakan faktor yang dapat memengaruhi penggunaan bahasa dalam masyarakat dwibahasa atau multibahasa. Dimensi itu mencakup umur, jenis kelamin, pekerjaan dan pendidikan. Namun, dalam penelitian ini hanya difokuskan pada dimensi peristiwa bahasa dan kategori umur. Fokus tersebut dapat menggambarkan pola pemilihan bahasa etnik Bugis di Kabupaten Donggala Kecamatan Sojol Utara.

\section{METODE}

Penelitian ini termasuk jenis penelitian lapangan dengan pendekatan sosiolinguistik. Oleh karena itu, pengkajian memakai pendekatan ilmu-ilmu sosial sebagaimana disarankan oleh Fasold (1984:183), suatu kajian sosiolinguistik melihat fenomena pemakaian bahasa sebagai fakta sosial yang menempatkan pemakaian (kode), sistem tingkah laku budaya yang berhubungan dengan pemakian bahasa dalam konteks yang sebenarnya.

Jenis data yang diambil berupa data kuantitatif dan kualitatif. Data kuantitatif diperoleh melalui penggunaan daftar tanyaan (kuesioner) berstruktur. Dalam kuesioner berstruktur, setiap pertanyaan disertai dengan alternatif jawaban secara lengkap atau kategori tertentu, (Aswantini, 2013:20). Data kualitatif diperoleh dengan teknik wawancara, observasi, dan perekaman berdasarkan teknik snowball sampling.

Penelitian ini berlokasi di Desa Ogoamas I dan Ogoamas II Kecamatan Sojol Utara Kabupaten Donggala. Kedua Desa tersebut dipilih karena merupakan basis komunitas etnik Bugis yang terbanyak dan masih jauh dari pengaruh lingkungan kota sehingga keaslian bahasa Bugis-nya masih nampak.

Berkaitan dengan itu, karena keterbatasan waktu penelitian, maka populasi penelitian ini hanya mengambil beberapa sampel sebagai objek yang diteliti atau hanya meneliti elemen sampel bukan elemen populasi. Jumlah sampel ditetapkan 92 responden dari 1017 jumlah penduduk kedua desa tersebut. Sebanyak 52 responden dari Desa Ogoamas I, dan 47 responden yang diambil dari Desa Ogoamas II. Perbedaan 
jumlah sampel tersebut karena populasi etnik Bugis di Desa Ogoamas I lebih banyak jika dibandingkan dengan populasi etnik Bugis yang ada di Desa Ogoamas II. Pengambilan sampel dilakukan dengan teknik sampel random (acak sederhana). Pengambilan 92 sampel tersebut diacak berdasarkan kategori pendidikan.

Hal itu sejalan dengan teori Gunarwan, (2002:46) yang mengatakan bahwa untuk penelitian kebahasaan, sampel yang besar cenderung tidak perlu. Hal itu karena perilaku linguistik lebih homogen dari pada perilaku-perilaku lain. Data yang diperoleh melalui kuesioner dianalisis dengan cara penghitungan persentase yang didasarkan pada jumlah jawaban yang masuk, Muhajir (1979:30). Jawaban yang masuk adalah jawaban responden tentang informasi bahasa yang digunakan ketika berkomunikasi dengan nenek/kakek, ayah/ibu, adik/kakak, putra/putri, dan suami istri bagi yang telah berkeluarga.

\section{PEMBAHASAN}

Pola penggunaan bahasa oleh etnik Bugis berdasarkan peristiwa bahasa dan kategori umur diarahkan untuk melihat fenomena perilaku berbahasa etnik Bugis berdasarkan peristiwa bahasa dan kategori umur. Kategori umur yang digunakan dalam tulisan ini ada empat kelompok, yaitu umur
11-15 tahun, umur 16-27 tahun, umur 28 - 49 tahun, dan umur 50 tahun ke atas. Selanjutnya, peritiwa bahasa yang digunakan dalam penelitian ini ada tiga, yaitu bercakap santai, marah-marah, dan bersenda gurau. Data tentang pemilihan bahasa Bugis oleh etnik Bugis dalam ranah keluarga berdasarkan peristiwa bahasa dan kategori umur di Kabupaten Donggala Kecamatan Sojol Utara diperoleh melalui jawaban responden dari pertanyaan yang terdaftar dalam kuesioner. Dalam kuesioner ditanyakan bahasa apakah yang digunakan responden ketika berbicara santai, marahmarah, dan bersenda gurau dengan kakek/nenek, ayah/ibu, kakak/adik, putra/putri, dan suami/istri (bagi responden yang sudah menikah), dan putra/putri (bagi responden yang sudah menikah) di rumah. Dalam pertanyaan tersebut terdapat empat pilihan jawaban, yaitu (a) bahasa Bugis, (b) bahasa Indonesia (c) campuran antara bahasa Bugis dan bahasa Indonesia, dan (d) bahasa lainnya yang ada di Kabupaten Donggala Kecamatan Sojol Utara. Keempat jawaban tersebut ditelaah berdasarkan dimensi identitas sosial yang mencakup kategori umur. 
a. Pola Pemilihan Bahasa Etnik Bugis tahun, dalam penelitian ini berjumlah 20 dalam Ranah Keluarga Berdasarkan responden dari 92 jumlah responden. Berikut Peristiwa Bahasa pada Kategori adalah tabel pola pemilihan bahasa oleh

\section{Umur 11-15 Tahun}

Kategori pemilihan bahasa etnik

Bugis dalam ranah keluarga berdasarkan etnik Bugis dalam ranah keluarga berdasarkan peristiwa bahasa dan kategori umur $11-15$ tahun.

peristiwa bahasa dan kategori umur $11-15$

Gambar 1 Pola Pemilihan Bahasa etnik Bugis dalam Ranah Keluarga Berdasarkan Peristiwa Bahasa (Bercakap Santai, Marah-Marah, Bersenda Gurau) pada Kategori Umur 11-15 Tahun

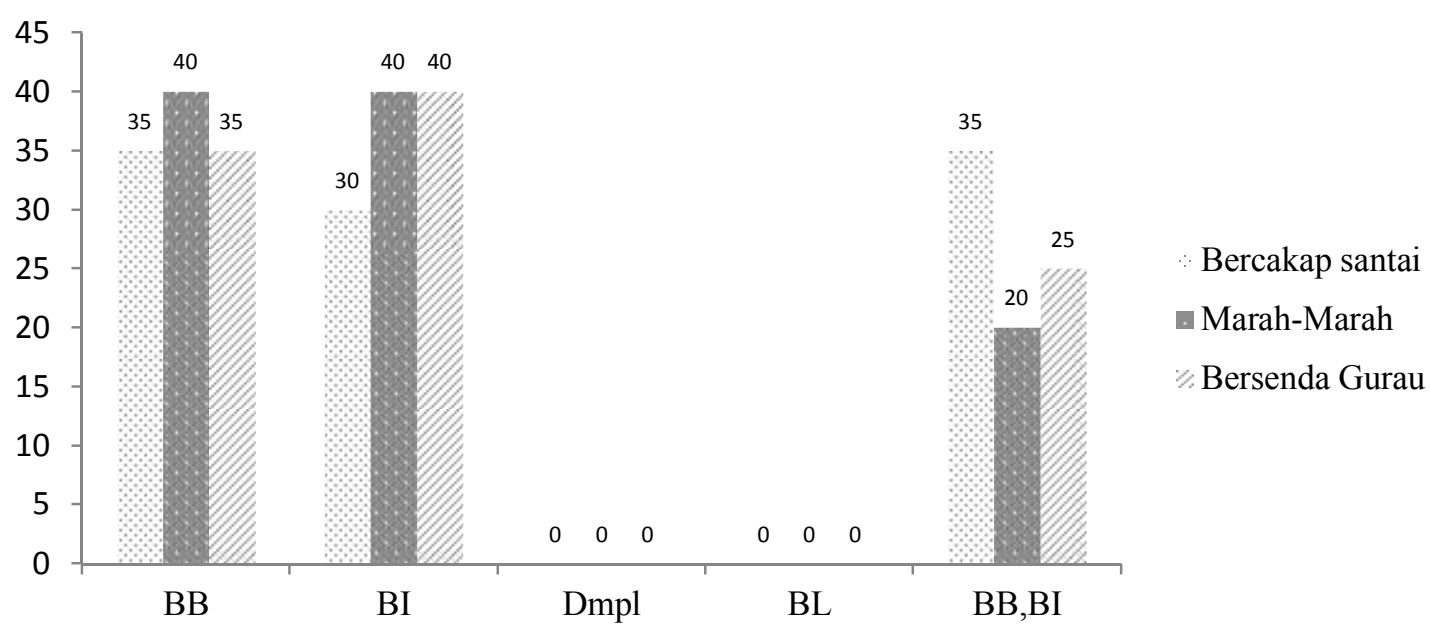

Sumber: data primer

Keterangan:

$\mathrm{BB}=$ bahasa Bugis

$\mathrm{BL}=$ bahasa lain

$\mathrm{BI}=$ bahasa Indonesia

$\mathrm{BB}, \mathrm{BI}=$ bahasa Bugis, bahasa Indonesia

B. Dmpl= bahasa Dampal

Berdasarkan gambar 1 terlihat pola kategori umur 11-15 tahun. Responden pemakaian bahasa etnik Bugis dalam ranah yang berumur $11-15$ tahun ketika keluarga berdasarkan peritiwa bahasa dan bercakap santai dengan keluarga sebanyak 
$35 \%$ yang menggunakan BB, sebanyak $30 \%$ yang menggunakan BI dan sebanyak 35\% yang bercampur kode menggunakan BI dan BB. Sementara BD dan BL yaitu bahasa yang ada di daerah tersebut tak satu pun responden yang menggunakan bahasa tersebut.

Selanjutnya, responden yang berumur 11-15 tahun apabila marah-marah bahasa yang digunakan dalam keluarga yaitu sebanyak 8 responden (40\%) yang menggunakan BB. Demikian juga yang menggunakan BI sebanyak 8 responden (40\%) bahasa yang digunakan apabila marahmarah dalam keluarga. Sementara, yang bercampur kode antara BI dan BB sebanyak 4 responden (20\%) yang digunakan oleh etnik Bugis yang berumur $11-15$ tahun apabila marah-marah dalam ranah keluarga. sementara BD dan BL tak satu pun responden yang memilihnya.

Lebih lanjut, responden yang berumur $11-15$ tahun apabila bersenda gurau dengan keluarga, sebanyak 7 responden (35\%) yang menggunakan $\mathrm{BB}, 8$ responden $(40 \%)$ yang menggunakan BI dan hanya 5 responden
(25\%) yang menggunakan bahasa campuran antara $\mathrm{BB}$ dan $\mathrm{BI}$.

Secara keseluruhan, pola pemilihan bahasa oleh etnik Bugis dalam ranah keluarga berdasarkan peristiwan bahasa dan kategori umur $11-15$ tahun sebanyak 37\% yang menggunakan $\mathrm{BB}$, demikian juga yang menggunakan BI sebanyak 37\%. Sementara, yang bercampur kode antara $\mathrm{BB}$ dan $\mathrm{BI}$ sebanyak $26 \%$.

Penggunaan $\mathrm{BB}$ dan $\mathrm{BI}$ berimbang yaitu $37 \%$. Hal tersebut menunjukkan bahwa pemilihan bahasa etnik Bugis kategori umur 11-15 tahun (remaja) mulai bergeser ke pemilihan BI yang lebih berprestise. Hal tersebut dipicu oleh pengaruh kemajuan ilmu pengetahuan dan teknologi, khususnya informasi. Hal itu berindikasi bahwa $10-15$ tahun yang akan datang pemilihan BB berdasarkan peristiwa bahasa akan bergeser ke pemilihan $\mathrm{BI}$.

Dengan demikian, dapat digambarkan pola pemilihan bahasa etnik Bugis dalam ranah keluarga berdasarkan peristiwa bahasa kategori umur $11-15$ tahun seperti berikut ini.

\begin{tabular}{|l|l|l|l|l|l|c|}
\hline \multirow{3}{*}{ No. } & \multirow{3}{*}{ Peristiwa Bahasa } & \multicolumn{6}{|c|}{ Pemilihan Bahasa } \\
\cline { 3 - 8 } & & $\mathbf{B B}$ & $\mathbf{B I}$ & $\mathbf{B . D m p l}$ & $\mathbf{B L}$ & BB,BI \\
\cline { 3 - 8 } & $\mathbf{\%}$ & $\mathbf{\%}$ & $\mathbf{\%}$ & $\mathbf{\%}$ & $\mathbf{\%}$ \\
\hline 1 & 2 & $\mathbf{3}$ & $\mathbf{4}$ & $\mathbf{5}$ & $\mathbf{6}$ & $\mathbf{7}$ \\
\hline 1 & Bercakap Santai & $35 \%$ & $30 \%$ & - & - & $35 \%$ \\
\hline 2 & Marah-Marah & $40 \%$ & $40 \%$ & - & - & $20 \%$ \\
\hline 3 & Bersenda Gurau & $35 \%$ & $40 \%$ & - & - & $25 \%$ \\
\hline
\end{tabular}


b. Pola Pemilihan Bahasa Etnik Bugis tahun, dalam penelitian ini terjaring 19 dalam Ranah Keluarga Berdasarkan responden dari 92 jumlah responden. Berikut Peristiwa Bahasa pada Kategori adalah tabel pola pemilihan bahasa oleh

Umur 16-27 Tahun

Kategori pemilihan bahasa etnik Bugis dalam ranah keluarga berdasarkan peristiwa bahasa dan kategori umur 16-27 etnik Bugis dalam ranah keluarga berdasarkan peristiwa bahasa dan kategori umur $16-27$ tahun.

Gambar 2 Pola Pemilihan Bahasa etnik Bugis dalam Ranah Keluarga Berdasarkan Peristiwa Bahasa (Bercakap Santai, Marah-Marah, Bersenda Gurau) pada Kategori Umur 16-27 Tahun

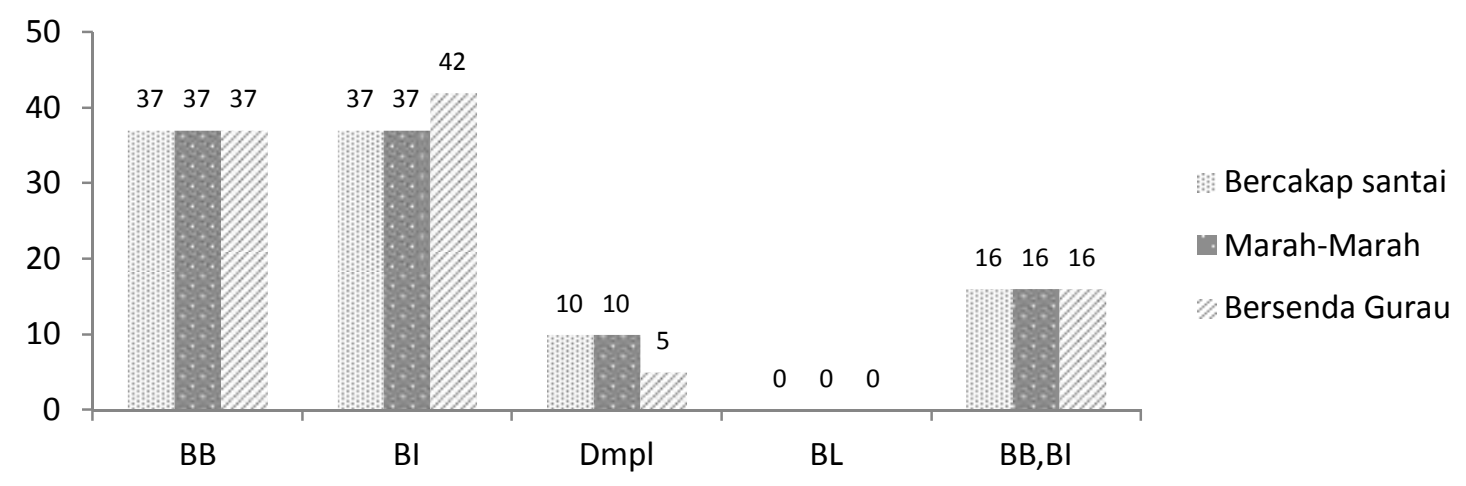

Sumber: data primer

Berdasarkan gambar 1 terlihat pola penduduk asli di Kecamatan Sojol Utara pemakaian bahasa etnik Bugis dalam ranah Kabupaten Donggala. Sementara, yang keluarga berdasarkan peritiwa bahasa pada bercampur kode antara BB dan BI dalam kategori umur 16-27 tahun. Responden penggunaan bahasa ketika bercakap santai yang berumur 16-27 tahun ketika sebanyak $16 \%$.

bercakap santai dengan keluarga sebanyak

Selanjutnya, responden yang berumur $37 \%$ yang menggunakan $\mathrm{BB}$, dan juga 16-27 tahun apabila marah-marah bahasa sebanyak $37 \%$ serta ada $10 \%$ yang yang digunakan dalam keluarga yaitu menggunakan BDmpl sebagai bahasa sebanyak 7 responden $(37 \%)$ yang 
menggunakan BB. Demikian juga yang menggunakan BI sebanyak 7 responden (37\%) yang digunakan oleh etnik Bugis apabila marah-marah dalam ranah keluarga. Hanya $10 \%$ atau hanya 2 responden yang menggunakan bahasa setempat yaitu BDmpl. Hal ini terjadi berdasarkan hasil wawancara terhadap responden karena terjadi perkawinan campur antara etnik Bugis dan etnik Dampal. Sementara, yang bercampur kode antara BI dan BB sebanyak 3 responden (16\%) yang digunakan oleh etnik Bugis yang berumur 16-27 tahun apabila marah-marah dalam ranah keluarga.

Lebih lanjut, responden yang berumur 16-27 tahun apabila bersenda gurau dengan keluarga, sebanyak 7 responden (37\%) yang menggunakan $\mathrm{BB}$, juga 7 responden (37\%) yang menggunakan BI dan hanya 1 responden $(5 \%)$ yang menggunakan bahasa penduduk asli yaitu Bdmpl. Sementara, yang menggunakan bahasa campuran antara $\mathrm{BB}$ dan BI sebanyak 3 responden (16\%).

Secara keseluruhan, pola pemilihan bahasa oleh etnik Bugis dalam ranah keluarga berdasarkan peristiwan bahasa dan kategori umur 16-27 sebanyak 37\% yang menggunakan $\mathrm{BB}, 39 \%$ yang menggunakan BI dan 8\% yang menggunakan bahasa setempat yaitu BDmpl. Sementara, yang bercampur kode antara BB dan BI sebanyak $16 \%$.
Berdasarkan hal tersebut, pemilihan BI lebih tinggi yaitu sebanyak 39\% dibanding dengan pemilihan BB hanya $37 \%$. Sementara, kategori umur 11-15 tahun pemilihan BB dan BI seimbang yaitu samasama mencapai 37\%. Hal ini bertentangan dengan teori yang mengatakan bahwa lebih tua umur seseorang lebih kuat penggunaan bahasa pertamanya (bahasa daerahnya). Sebaliknya, lebih muda usia seseorang lebih lemah penggunaan bahasa pertamanya (bahasa daerahnya). Berdasarkan hasil pengamatan dan wawancara penulis terhadap responden hal ini terjadi karena mulai umur 0-15 tahun anak-anak mereka diajarkan BB dengan tujuan agar kelak anak mereka dapat ber-BB dan tetap memepertahankan bahasanya dan budayanya. Sementara, kategori umur 16-27 tahun penggunaan BI lebih tinggi dibanding dengan penggunaan $\mathrm{BB}$, berdasarkan hasil pengamatan dan wawancara hal ini terjadi karena pada umur tersebut anak-anak telah memasuki sekolah menengah atas sehingga terpengaruh dengan bahasa anak-anak lainnya yang berasal dari etnik lain yang menggunakan BI.

Dengan demikian, dapat digambarkan pola pemilihan bahasa etnik Bugis dalam ranah keluarga berdasarkan peristiwa bahasa kategori umur 16-27 tahun seperti berikut ini. 


\begin{tabular}{|l|l|l|c|c|c|c|}
\hline \multirow{2}{*}{ No. } & \multirow{2}{*}{ Peristiwa Bahasa } & \multicolumn{6}{|c|}{ Pemilihan Bahasa } \\
\cline { 3 - 8 } & & BB & BI & B.Dmpl & BL & BB,BI \\
\cline { 3 - 8 } & & $\%$ & $\%$ & $\%$ & $\%$ & $\%$ \\
\hline 1 & 2 & 3 & 4 & 5 & $\mathbf{6}$ & 7 \\
\hline 1 & Bercakap Santai & $37 \%$ & $37 \%$ & $10 \%$ & - & $16 \%$ \\
\hline 2 & Marah-Marah & $37 \%$ & $37 \%$ & $10 \%$ & - & $16 \%$ \\
\hline 3 & Bersenda Gurau & $37 \%$ & $42 \%$ & $5 \%$ & - & $16 \%$ \\
\hline
\end{tabular}

c. Pola Pemilihan Bahasa Etnik Bugis peristiwa bahasa dan kategori umur 28-49 dalam Ranah Keluarga Berdasarkan tahun, dalam penelitian ini terjaring 38 Peristiwa Bahasa pada Kategori responden dari 92 jumlah responden. Berikut Umur 28-49 Tahun

Kategori pemilihan bahasa etnik Bugis dalam ranah keluarga berdasarkan adalah tabel pola pemilihan bahasa oleh etnik Bugis dalam ranah keluarga berdasarkan peristiwa bahasa dan kategori umur 28-49 tahun.

Gambar 3 Pola Pemilihan Bahasa etnik Bugis dalam Ranah Keluarga Berdasarkan Peristiwa Bahasa (Bercakap Santai, Marah-Marah, Bersenda Gurau) pada Kategori Umur 28-49 Tahun

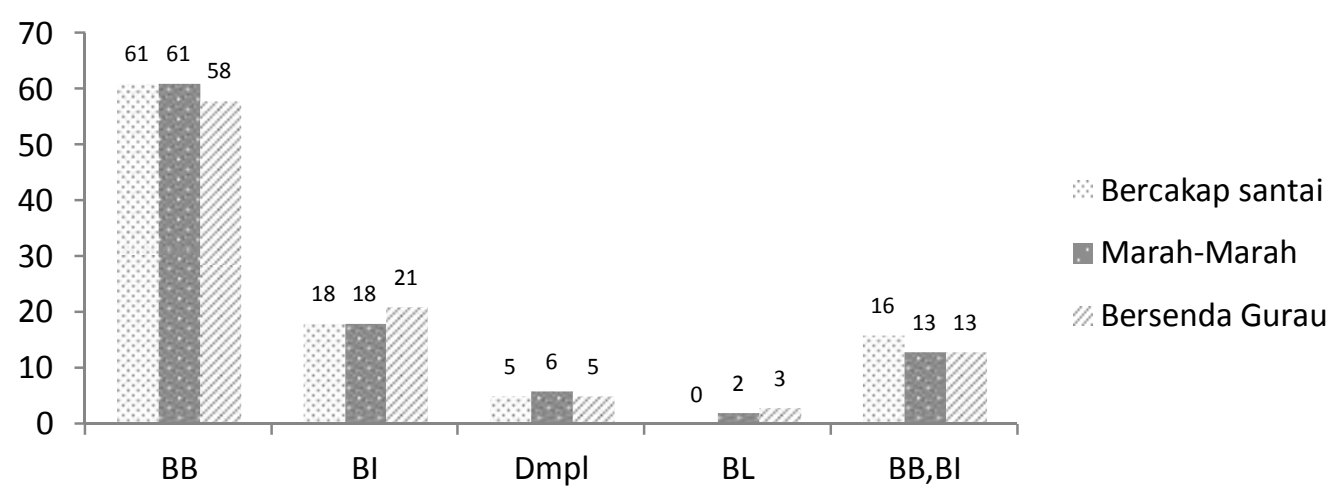

Sumber: data primer 
Berdasarkan gambar 3 terlihat pola pemakaian bahasa etnik Bugis dalam ranah keluarga berdasarkan peritiwa bahasa pada kategori umur 28-49 tahun. Responden yang berumur 28-49 tahun ketika bercakap santai dengan keluarga sebanyak $61 \%$ yang menggunakan $\mathrm{BB}, 18 \%$ yang menggunakan BI serta ada $5 \%$ yang menggunakan BDmpl sebagai bahasa penduduk asli di Kecamatan Sojol Utara Kabupaten Donggala. Sementara, yang bercampur kode antara BB dan BI dalam penggunaan bahasa ketika bercakap santai sebanyak $16 \%$.

Selanjutnya, responden yang berumur 28-49 tahun apabila marah-marah bahasa yang digunakan dalam keluarga yaitu sebanyak 23 responden (61\%) yang menggunakan BB. Demikian juga yang menggunakan BI sebanyak 7 responden (18\%) yang digunakan oleh etnik Bugis apabila marah-marah dalam ranah keluarga. Hanya $6 \%$ atau hanya 2 responden yang menggunakan bahasa setempat yaitu BDmpl, dan ada $2 \%$ yang menggunakan $\mathrm{BL}$ yaitu bahasa Mandar. Adanya penggunaan BL yaitu bahasa Mandar, hal ini terjadi berdasarkan hasil wawancara terhadap responden karena terjadi perkawinan campur antara etnik Bugis dan etnik Mandar. Sementara, yang bercampur kode antara BI dan BB sebanyak 5 responden (13\%) yang digunakan oleh etnik Bugis yang berumur 28-49 tahun apabila marah-marah dalam ranah keluarga.

Lebih lanjut, responden yang berumur 28-49 tahun apabila bersenda gurau dengan keluarga, sebanyak 22 responden (58\%) yang menggunakan $\mathrm{BB}$, dan ada 8 responden (21\%) yang menggunakan BI dan hanya 2 responden $(5 \%)$ yang menggunakan bahasa penduduk asli yaitu Bdmpl serta ada 1 responden (3\%) yang menggunakan BL yaitu bahasa Mandar. Sementara, yang menggunakan bahasa campuran antara BB dan BI sebanyak 5 responden (13\%).

Secara keseluruhan, pola pemilihan bahasa oleh etnik Bugis dalam ranah keluarga berdasarkan peristiwan bahasa dan kategori umur 28-49 tahun sebanyak 60\% yang menggunakan BB, 19\% yang menggunakan BI dan 5\% yang menggunakan bahasa setempat yaitu BDmpl serta ada 2\% responden yang menggunakan BL yaitu bahasa Mandar. Sementara, yang bercampur kode antara BB dan BI sebanyak 14\%.

Dengan demikian, dapat digambarkan pola pemilihan bahasa etnik Bugis dalam ranah keluarga berdasarkan peristiwa bahasa pada kategori umur 28-49 tahun seperti berikut ini. 


\begin{tabular}{|c|c|c|c|c|c|c|}
\hline \multirow{3}{*}{ No. } & \multirow{3}{*}{ Peristiwa Bahasa } & \multicolumn{5}{|c|}{ Pemilihan Bahasa } \\
\hline & & BB & BI & B.Dmpl & BL & BB,BI \\
\hline & & $\%$ & $\%$ & $\%$ & $\%$ & $\%$ \\
\hline 1 & 2 & 3 & 4 & 5 & 6 & 7 \\
\hline 1 & Bercakap Santai & $61 \%$ & $18 \%$ & $5 \%$ & - & $16 \%$ \\
\hline 2 & Marah-Marah & $61 \%$ & $18 \%$ & $6 \%$ & $2 \%$ & $13 \%$ \\
\hline 3 & Bersenda Gurau & $58 \%$ & $21 \%$ & $5 \%$ & $3 \%$ & $13 \%$ \\
\hline
\end{tabular}

d. Pola Pemilihan Bahasa Etnik Bugis peristiwa bahasa dan kategori umur di atas 50 dalam Ranah Keluarga Berdasarkan tahun, dalam penelitian ini terjaring 15 Peristiwa Bahasa pada Kategori responden dari 92 jumlah responden. Berikut

\section{Umur di Atas 50 Tahun}

Kategori pemilihan bahasa etnik Bugis dalam ranah keluarga berdasarkan adalah tabel pola pemilihan bahasa oleh etnik Bugis dalam ranah keluarga berdasarkan peristiwa bahasa dan kategori umur di atas 50 tahun.

Gambar 4 Pola Pemilihan Bahasa etnik Bugis dalam Ranah Keluarga Berdasarkan Peristiwa Bahasa (Bercakap Santai, Marah-Marah, Bersenda Gurau) pada Kategori Umur di Atas 50 Tahun

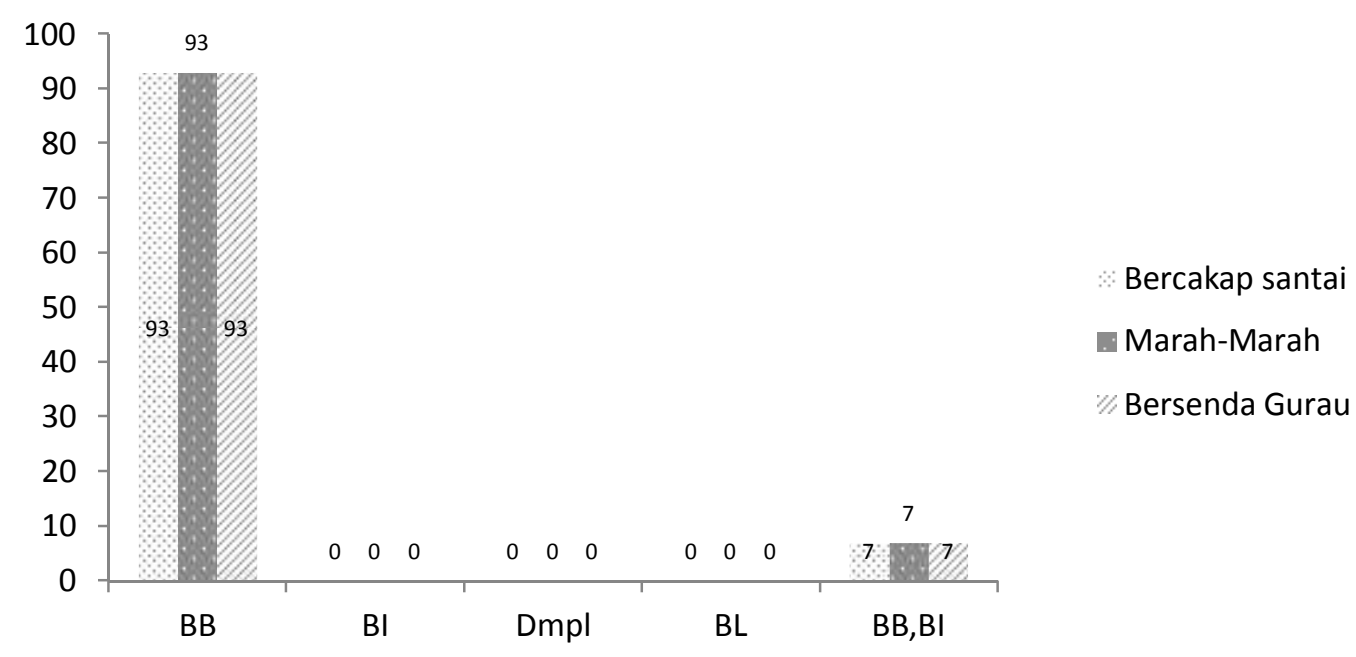

Sumber: data primer 
Berdasarkan gambar 4 terlihat pola pemakaian bahasa etnik Bugis dalam ranah keluarga berdasarkan peritiwa bahasa pada kategori umur di atas 50 tahun. Responden yang berumur di atas 50 tahun ketika bercakap santai dengan keluarga sebanyak 93\% yang menggunakan BB dan hanya 7\% yang bercampur kode antara BI dan BB. Sementara tak satu pun respodnen yan menggunakan BI, BDmpl, dan BL.

Demikian juga responden yang berumur di atas 50 tahun apabila marahmarah bahasa yang digunakan dalam keluarga yaitu sebanyak $93 \%$ yang menggunakan $\mathrm{BB}$ dan hanya $7 \%$ yang bercampur kode antara BI dan BB. Sementara tak satu pun respodnen yan menggunakan BI, BDmpl, dan BL. Sementara, apabila bersenda gurau juga sebanyak 93\% yang menggunakan $\mathrm{BB}$ dan hanya 7\% yang bercampur kode antara BI dan BB. Sementara tak satu pun respodnen yan menggunakan BI, BDmpl, dan BL.
Lebih lanjut, responden yang berumur 28-49 tahun apabila bersenda gurau dengan keluarga, sebanyak 22 responden (58\%) yang menggunakan $\mathrm{BB}$, dan ada 8 responden (21\%) yang menggunakan BI dan hanya 2 responden $(5 \%)$ yang menggunakan bahasa penduduk asli yaitu Bdmpl serta ada 1 responden (3\%) yang menggunakan BL yaitu bahasa Mandar. Sementara, yang menggunakan bahasa campuran antara BB dan BI sebanyak 5 responden (13\%).

Secara keseluruhan, pola pemilihan bahasa oleh etnik Bugis dalam ranah keluarga berdasarkan peristiwan bahasa dan kategori umur di atas 50 tahun pada umumnya menggunakan BB yaitu sebanyak 93\% sementara hanya 7\% yang bercampur kode antara BB dan BI. Hal ini terjadi karena pada umumnya responden yang berumur di atas 50 tahun masih sangat loyal dalam mempertahankan bahasa dan budayanya.

Dengan demikian, dapat digambarkan pola pemilihan bahasa etnik Bugis dalam ranah keluarga berdasarkan peristiwa bahasa pada kategori umur di atas 50 tahun. seperti berikut ini. 


\begin{tabular}{|l|l|c|c|c|c|c|}
\hline \multirow{3}{*}{ No. } & \multirow{3}{*}{ Peristiwa Bahasa } & \multicolumn{6}{|c|}{ Pemilihan Bahasa } \\
\cline { 3 - 8 } & & BB & BI & B.Dmpl & BL & BB,BI \\
\cline { 3 - 8 } & & $\%$ & $\%$ & $\%$ & $\%$ & $\%$ \\
\hline 1 & 2 & $\mathbf{3}$ & $\mathbf{4}$ & $\mathbf{5}$ & $\mathbf{6}$ & $\mathbf{7}$ \\
\hline 1 & Bercakap Santai & $93 \%$ & - & - & - & $7 \%$ \\
\hline 2 & Marah-Marah & $93 \%$ & - & - & - & $7 \%$ \\
\hline 3 & Bersenda Gurau & $93 \%$ & - & - & - & $7 \%$ \\
\hline
\end{tabular}

\section{SIMPULAN}

Pola pemilihan bahasa etnik Bugis di Kabupaten Donggala dalam ranah keluarga berdasarkan peristiwa bahasa dan kategori umur responden yang berumur $11-15$ tahun rata-rata memilih $\mathrm{BB}$ hanya $37 \%$ dan yang memilih BI juga sebanyak 37\%, sisanya bercampur kode antara BB dan BI yaitu 26\%. Demikian juga responden yang berumur 16-27 tahun pemilihan BB hanya 37\% dan BI lebih banyak yaitu $39 \%$, sisanya responden memilih bercampur kode antara BB dan BI sera juga ada yang memilih bahasa setempat yaitu bahasa Dampal. Selanjutnya responden yang berumur 2849 tahun pada umumnya memilih BB sebagai bahasa utama dalam keluarga yaitu sebanyak $60 \%$. Lebih lanjut responden yang berumur di atas 50 tahun pada umumnya memilih BB sebagai bahasa utama dalam keluarga yaitu $93 \%$.

Faktor-faktor yang mendasari pemilihan bahasa $\mathrm{BB}$ oleh etnik Bugis dalam ranah keluarga berdasarkan peristiwa bahasa pada kategori umur di Kabupaten Donggala adalah faktor sikap positif terhadap bahasanya yaitu BB. Di samping itu, etnik Bugis fanatik terhadap bahasanya walaupun berada di perantauan. Di samping itu, etnik Bugis loyalitas terhadap bahasanya, bahasa Bugis, bangga terhadap bahasanya, bahasa Bugis, dan adanya kesadaran norma bahasa, dalam bahasa Bugis 


\section{DAFTAR PUSTAKA}

Amir, Johar. 2010. "Pola Pemilihan Bahasa pada Ranah Keluarga di Kabupaten Pangkajene Kepulauan”. Disertasi. Makassar: Universitas Hasanuddin.

Aswantini, 2013. "Sumber dan Koleksi Data (Bidang IPS)". Modul. Diklat Jabatan Fungsional Peneliti Tingkat Pertama. Bogor: Lembaga Ilmu Pengetahuan Indonesia. (rujukan Buku)

Aziz, E. Aminudin. 2003. "Usia dan Realisasi Kesantunan Berbahasa: Sebuah Studi Pragmatik pada Para Penutur Bahasa Indonesia”. Dipublikasikan dalam PELBBA 16 (Kumpulan Makalah Pertemuan Linguistik Pusat Kajian Bahasa Atma Jaya: Keenam Belas). Jakarta: Yayasan Obor Indonesia.

Bell, T. Roger. 1976. Sociolinguistics: Goals, Approaches, and Problems. London: B.T. Batsford Ltd.

Chaer, Abdul., Leonie Agustina. 2010. Sosiolinguistik: Perkenalan Awal (Edisi Revisi). Jakarta: PT. Rineka Cipta.

Ervin-Tripp, S.M. 1972. "Sociolinguistic Rules of Address". Dalam John B. Pride

and Janet Holmes (eds.) Sociolinguistics. Harmondsworth: Penguin, 225 - 240.
Fasold, Ralph. 1984. The Sociolinguistic of Society. Oxford: Basil Blackwell. (rujukan Buku)

Fishman, J.A. 1970. Sociolinguistics: A Brief Introduction. Rowly-Massachusett: Newbury House. 1972 (Ed). The Sociology of Language. Newbury House: Rouley Mas.

1976. "The Relationship between Micro and Macro Sociolinguistics in The Study Who Speaks What Language to Whom and When" dalam Pride dan Holmes (Ed).

Muhajir. 1979. Fungsi dan Kedudukan Dialek Jakarta: Jakarta: Pusat Pembinaan dan Pengembangan Bahasa. (rujukan Buku)

Platt, J.T. 1977. Code Selection in a Multilingual Polyglossic Society. Oxford: Pergamon Press. (rujukan Buku)

Singh, Ishtla and Jean Stilwell Peccei (eds.). 2004. Language, Society, and Power. New York: Routledge.

Wijana, I Dewa Putu., Muhammad Rohmadi. 2012. Sosiolinguistik: Kajian Teori dan Analisis. Yogyakarta: Pustaka Pelajar. 